\title{
Transition Countermeasures for Sustainable Development of Social Sports and School Sports
}

\author{
Shiqi Lu \\ College of Management, Beijing Sport University, Beijing, 100084
}

Keywords: Social sports; school sports; sustainable development; transition countermeasures

\begin{abstract}
With the rapid economic development of China at present, the problem of environmental pollution is becoming increasingly more serious, and people are more aware of the importance of physical health due to various diseases brought by environmental pollution. Therefore, people put forward the slogan that conforms to the needs of contemporary social development: "All the people have exercises to keep physical and mental health", so that social sports develop in an all-round way. Sports mainly include social sports and school sports, which complement each other and need to maintain multi-aspect interactive development in multiple forms and multi-content coordinated development. Therefore, in the general trend that all the people have exercises, it is necessary for social sports and school sports to find right breakthrough points to reflect their own value, so that both are integrated to provide guarantee for people's physical health.
\end{abstract}

\section{Introduction}

With the constant social progress, the high speed economic development of China promotes deep educational reform whilst gradually improving people's living standard and quality, so that people pay more attention to their health conditions. At present, the sports undertakings of China develop very fast, and various sports venues are built like mushrooms after rain, so that the concept of sports enjoys popular support. Sports play a very important role in people's daily life, become an indispensable part of people's life, and also create a good living environment for the development of social sports and school sports. Therefore, social sports and school sports must be organically combined, give full play to their advantages and roles, and guarantee comprehensive healthy development of the people, so as to lay the good and solid foundation for building a harmonious and healthy sports society. This paper provides referenceable suggestions for promoting development of social sports and teaching reform of school sports through researches mainly from the perspectives of the interrelation between social sports and school sports, and the transition countermeasures for sustainable development of social sports and school sports.

\section{Interrelation between social sports and school sports}

Based on physical exercises of students, school sports aim to enhance students' physical quality, enable students to master the most basic theoretical knowledge of sports exercises and sport skills during exercise whilst cultivating students' lifelong sports consciousness, promote comprehensive development of students' physical and mental health, and are an excellently organized and planned cultural and educational campaign. The object of social sports is all social workers, the natural living environment and diversified sports facilities of people lays the foundation for satisfying people's demand for fitness and bodybuilding, and social sports are a physical exercise campaign in which all the people can participate.

School sports are the foundation for social sports, and are also closely related to social sports. By a series of sports teaching activities, school sports cultivate students' cognition of lifelong sports, enrich students' experience in sports, and improve students' exercise skills, so that students can be quickly integrated into social sports after leaving school. Furthermore, school sports also cultivate a large number of professional talents for social sports, thereby promoting healthy, steady and rapid development of social sports in China. 
Social sports are extension of school sports. Students not only can participate in sports activities organized by schools, but also should take an active part in some sports activities outside schools, so as to enable students to improve their cognition of the integration of school, society and family. Developing social sports activities not only gives play to professional advantages of schools in the aspects of talents and knowledge, but also exercise students' body, mind and will, greatly stimulates students' potential, arouses students' enthusiasm, and provides guarantee for healthy physical and mental development of students.

At present, school sports mainly develop in campus of China. Student are trained and exercised about relevant sports exercise knowledge by using existing sports exercise equipment in schools or purchasing corresponding teaching equipment, so that students seldom have chances to contact with outside social sport exercises. This educational mode is relatively closed. Under the circumstance, it is also very difficult for students to apply sports exercise knowledge and technology learned in school to outside society, thus losing enthusiasm for participation in social sports activities. The development place of social sports has certain regional restrictions, various sports venues are privately run on small construction scales, and there are a few sports venues. Sports activities still need to be charged correspondingly, thereby scaring off a lot of sports fans.

\section{Transition countermeasures of social sports and school sports}

Ensuring smooth transition between social sports and school sports is the key to keeping sustainable development of sports undertakings in China. The transition between both includes not only materials, but also consciousness, and is a systemic sports activity involving schools and society. Therefore, it is necessary to cultivate people's lifelong sports consciousness from the perspective of lifelong sports, and each strategy needs to be implemented based on full cooperation and support of people, so that people fully realize the advantages of sports fitness among all the people, and actively throw themselves into the practice of lifelong sports.

The development of social sports is driven by the national development, so sports teaching in schools should also conform to the requirements of national development and social sports development, cultivate students' sports exercise ideas using the advantages of school teaching resources, and gradually enter the lifelong sports mode. First of all, schools need to strengthen propaganda and guide students to actively participate in school sports and social sports, so that students realize that life originates from sports. Secondly, diversified teaching modes are used to enable the sports teaching class atmosphere to be more active, different exercise modes are carried out based on students' characters and interests, and stress is laid on cultivating students' special skills whilst comprehensively cultivating students' sports exercises, so that students form good habits of sports exercises to cultivate their lifelong sports consciousness.

Nowadays, students are the most vigorous force in the whole society, and lead the social trend. In the aspect of sports exercises, their sports exercise behaviors also have an effect of moving and inspiring social workers. Therefore, schools need to strengthen cultivation of students' lifelong physical ability. Especially, professional sports colleges and universities are more ought to put cultivation of students' lifelong sports ability in the first place, set relevant professional courses, encourage students to participate in social sports exercises in the identity of volunteers, improve their sports ability whilst accumulating sports experiences, and inject new vitality into social sports of China.

At present, social sports and school sports of China have not been fully integrated in practice, and the data exchange between both has not met people's expectations. According to the development of the system theory, social sports and school sports are two branches of lifelong sports, and can realize the coordinated development of lifelong sports only by full integration and information exchange. A sports club is a recently popular form of sports organization, is a platform of integration of social sports and school sports in practice, and is also an important platform for people to cultivate independent sports exercise ability.

First of all, school sports should actively give play to the advantages of professional talents. In recent years, school sports in China have achieved very good results in the aspect of sports, 
introduced excellent physical education teachers, set professional sports courses, and trained a large number of professional talents for social sports, who have also obtained amazing awards in social sports training, competition and activities. Secondly, sports facilities in schools also need to be open to the outside world. At present, all colleges and universities in China have certain scales of sports venues, and have certain number of related sports facilities, and these sports resources can be shared. Schools can set up some courses, enable students to have in-depth communication and interaction with social personnel in sports activities, can also hold some sport events with the help of sponsors, and invest the income obtained therefrom into school sports equipment, so as to realize the mutual benefit of school sports and social sports. Finally, social sports venues should also appropriately reduce exercise charge standards, so that students can have access to sports venues outside schools for sports exercises, thereby realizing complementation and sharing of sport resources in China.

In the process of the development of sports undertakings in China, China needs to not only vigorously advocate all citizens to participate in sports exercises, but also prevent some unexpected events. Therefore, it is necessary to establish relevant sound sports mechanisms, so as to guarantee public security of China, and improve the social stability. Especially, as many as tens of thousands of people participate in popular large sport events in recent years, such as large marathons, football games, basketball games and so on. Therefore, full prevention schemes shall be formulated before games, and personnel evacuation shall be promptly prepared to avoid occurrence of violence in major sports activities. Therefore, it is very necessary to establish a relatively sound sports mechanism for sustainable development of social sports and school sports, which is also indispensable to maintain the national stability.

\section{Conclusion}

With the continuous development of society, social sports and school sports have also gradually revealed their respective advantages, are associated with each other and influence each other. The interaction between them in many aspects, such as sports talents, sports facilities, has also promoted steady development of sports undertakings in China. Therefore, in order to meet people's demand for sports and healthy development in the new era, China should pay more attention to the development of school sports, promote rapid development of social sports through healthy development of school sports, then enable all the people to be involved in sports, and improve people's physical quality whilst improving people's health level, so that people's life style is more healthy, thereby promoting harmonious social development in China.

\section{References}

[1] Wang Pingli. Supporting System of Sustainable Development of Social Sports of Physical Education [J]. Fujian Sports Science and Technology, 2012 (5): 59-61.

[2] Guo Xixian. Research on Interactive Development between School Sports and Social Sports [J]. Physical Observation, No. 1, 2013.

[3] Lv Wei. Study on Interactive Development between School Sports and Social Sports [J]. Attentions to Viewpoints, No. 7, 2013.

[4] Wang Kaizhen \& Li Xiaotian. Research on the Current Situation and Affecting Factors of the Openess of School Sports Facilities in China's Cities [J]. Journal of Beijing Sport University, 2011, 34 (7): 3. 